\title{
Implications of Social Distancing Policies on Drinking Water Infrastructure: An Overview of the Challenges to and Responses of U.S. Utilities during the COVID-19 Pandemic
}

\author{
Lauryn A. Spearing, Nathalie Thelemaque, Jessica A. Kaminsky, Lynn E. Katz, Kerry A. Kinney, \\ Mary Jo Kirisits, Lina Sela, and Kasey M. Faust*
}

Cite This: https://dx.doi.org/10.1021/acsestwater.0c00229

Read Online

ABSTRACT: Social distancing policies (SDPs) implemented throughout the United States in response to COVID-19 have led to spatial and temporal shifts in drinking water demand and, for water utilities, created sociotechnical challenges. During this unique period, many water utilities have been forced to operate outside of design conditions with reduced workforce and financial capacities. Few studies have examined how water utilities respond to a pandemic; such methods are even absent from many emergency response plans. Here, we documented how utilities have been impacted by the COVID-19 pandemic. We conducted a qualitative analysis of 30 interviews with 53 practitioners spanning 28 U.S. water utilities. Our aim was to, first, understand the challenges experienced by utilities and changes to operations (e.g., demand and deficit accounts) and, second, to document utilities' responses. Results showed that to maintain service continuity and implement SDPs, utilities had to overcome various challenges. These include supply chain issues, spatiotemporal changes in demand, and financial losses, and these challenges were largely dependent on the type of customers served (e.g., commercial or residential). Examples of utilities' responses include proactively ordering extra supplies and postponing capital projects. Although utilities' adaptations ensured the immediate provision of water services, their responses might have negative repercussions in the future (e.g., delayed projects contributing to aging infrastructure).

KEYWORDS: drinking water, pandemic planning, infrastructure management, population dynamics, social distancing policies

\section{INTRODUCTION}

The COVID-19 pandemic has drastically changed, at least temporarily, the way society, businesses, and infrastructure systems operate. In March 2020, local governments throughout the United States enacted a number of social distancing policies (SDPs), encouraging people to stay home and limit gatherings. These SDPs impacted water utility operations, as utilities had to ensure continuous services and the safety of their staff, while in many cases operating beyond their budgets and design conditions. The American Water Works Association (AWWA) found, for example, that utilities faced obstacles concerning workforce management, revenue loss, and supply chain for personal protective equipment (PPE). ${ }^{1}$

In general, utilities were challenged to quickly implement SDPs in their operations, often without guidance from their emergency response plans even though previous reports identified pandemics as a potential hazard to water systems. ${ }^{2,3}$ One such study ${ }^{4}$ investigated utilities' preparedness for pandemics using a survey of 50 Ohio utilities. Their study discussed potential issues (e.g., employee absenteeism and supply chain issues) and provides a template for pandemic plans. More recent work that focuses on COVID-19 has started to fill the gap in the pandemic planning literature for the water sector ${ }^{5-9}$ as well as for other infrastructure systems (e.g., wastewater ${ }^{10,11}$ ). For instance, Cotterill et al. ${ }^{9}$ utilized a survey deployed in the U.K. to understand the impact of COVID-19 on the water sector. They found that a range of challenges can arise (e.g., IT-related along with health and well-being) and that communication is critical when responding to a pandemic. In a recent commentary, $\mathrm{Neal}^{5}$ discussed how COVID-19 has impacted the water sector and systems dependent on water, such as food production and industry. Neal described COVID-19 as a threat multiplier and recommends improved governance approaches. Similarly, Sowby ${ }^{6}$ reviewed emergency preparedness policies by

Received: November 5, 2020

Revised: December 18, 2020

Accepted: December 21, 2020 
anecdotally discussing utilities' experiences during the COVID19 pandemic. Other work ${ }^{7}$ has focused on technology in the water sector, hypothesizing that the COVID-19 pandemic will accelerate the ongoing water sector digital revolution. ${ }^{12}$ Aside from the focus on water sector management during COVID19, researchers have also started to investigate how social distancing has impacted water demand. ${ }^{13,14}$ A study based in southern Italy discovered that people used water differently when SDPs were enacted (e.g., delayed morning peak and no lunchtime peak) and that the absence of commuters led to noticeable demand decreases in certain cities. Overall, there was a lack of pandemic-focused literature for the water sector before COVID-19, but in response, many researchers are now beginning to study the implications of pandemics on water infrastructure systems.

In addition to examining the pandemic-specific literature, we turn to population dynamics to understand SDPs as they can be conceptualized as a form of population change (i.e., the spatial demands on a system change when businesses close and some people work from home). Previous research has investigated water infrastructure system management in shrinking (i.e., cities that face population decline), ${ }^{95}$ urbanizing, ${ }^{16}$ gentrifying, ${ }^{17}$ and hosting ${ }^{18}$ cities (i.e., cities that receive displaced populations). Researchers have recognized that water infrastructure systems struggle to adapt to population dynamics due to limited flexibility with fixed systems designed to operate under specific conditions and government regulations. ${ }^{16}$ The process of urbanization, for instance, can complicate existing infrastructure plans and create the need for capital projects, which might be challenging to fund. Faust and colleagues $^{15,19,20}$ studied extensively how shrinking cities manage water infrastructure, finding that utilities struggle to decommission water infrastructure. Faure and Faust ${ }^{17}$ studied water infrastructure operations in gentrifying areas, focusing on altered sociodemographics and density. Existing work has explored many types of population dynamics, but to the best of our knowledge, researchers have yet to frame pandemicinduced SDPs as population dynamics when studying water infrastructure management. Notably, studies focused on capturing how demand changes (i.e., human-infrastructure interactions) impact the performance of water systems enable researchers to understand system vulnerabilities and leverage points (i.e., how an action might impact system performance). ${ }^{21}$

The existing literature on pandemic planning and population dynamics for water utilities is limited. As such, we have little knowledge of how water utilities adapt and respond to pandemics. Although recent studies have begun to fill this gap, scholars have recognized that researchers might be able to identify large-scale challenges and clarify results from existing COVID-19 research in the water sector by conducting semistructured interviews. ${ }^{9}$ Hence, we use semistructured interviews to document the experience, during the COVID-19 pandemic, of U.S. drinking water utilities. Our aim is twofold: (1) to understand the changes to system operations and challenges faced by utilities and (2) to study their response to challenges emerging during the pandemic. Our study is enabled by an inductive qualitative analysis of interviews and focus groups from 28 utilities. Our work on water utility operations during a pandemic will provide further theoretical evidence to underpin future research into the necessity of incorporating diverse water use profiles and consideration of population dynamics for resilient operations.
By exploring the implications of SDPs on water utilities, utilities can learn about more proactive approaches that will be immediately relevant if there are additional waves in the COVID-19 pandemic. A research area that has been of great interest to both national and global organizations ${ }^{2,22}$ is building a set of best practices and increasing utility resilience to future extreme events. The first step in enhancing this research area is to collect and analyze data to identify a range of approaches employed. Notably, operational data and institutional experiences often go unpreserved in utility records. In this study, we capture and document these lessons learned, which would otherwise erode with time and personnel changes. The results of our study will provide valuable information to utilities as they plan for future disasters or develop continuity plans. In fact, during the initial weeks of COVID-19, a survey of U.S. utilities found that only $55 \%$ of utilities had a business continuity plan, while an additional $27 \%$ of utilities were in the process of developing one. $^{23}$

\section{MATERIALS AND METHODS}

Serving as data for this study are 26 semistructured interviews and four focus groups (with four or more interviewees) with water utilities across the United States. Importantly, interviewees considered the gathering of pandemic planning information to be important and were willing to share their insight and learn from one another. Although some utilities in our study provide multiple infrastructure services (e.g., wastewater), we tailored the interviews and qualitative analysis around the provision of drinking water. This includes processes involved in treating water for drinking (e.g., operations facilities and testing), distributing water to users, maintaining physical infrastructure, and managing this process (e.g., supply chain for treatment chemicals or testing equipment, managing workforce, and customer relations). We studied the roles of multiple utility employees such as operators, maintenance field staff, lab staff that perform regulatory testing, customer service representatives, and managers. The qualitative analysis examined how these processes were disrupted by the COVID-19 pandemic (reducing face-to-face contact with customers, adjusting workflow to ensure social distancing, changed water demands, etc.).

2.1. Data Sources and Collection. Interviewees were selected using both convenience and snowball sampling. We first utilized our professional network to contact practitioners at utilities across the United States (i.e., convenience sampling). At the end of each interview, we asked the interviewee for contact recommendations (i.e., snowball sampling). Interviews were conducted until theoretical saturation of ideas was met, meaning no new information emerged during multiple interviews. ${ }^{26}$ Prior to data collection, the interview questions were reviewed by the Institutional Review Board at The University of Texas at Austin and The University of Washington. Participants were invited to participate through email, and interviews were conducted using online video conferencing, recorded (with permission), and transcribed. Interviews were approximately one hour in duration. The interview process started on June 8, $2020(\sim 3$ months after federal social distancing recommendations were enacted $^{25}$ ) and ended on August 3, 2020. The data set represents insight from 53 utility employees at 28 utilities spanning 13 states. See Table 1 for more details about interviewees. Size classifications are based on the U.S. Environmental Protection Agency's Community Water System 
Table 1. Information about Respondents

\begin{tabular}{|c|c|c|c|}
\hline state & $\begin{array}{l}\text { no. of } \\
\text { interviewees }\end{array}$ & roles & $\begin{array}{c}\text { EPA size classification } \\
\text { customers) }\end{array}$ \\
\hline Alabama & 1 & Water Resources Management Director & $10,001-100,000$ \\
\hline Arizona & 1 & Water Director & $10,001-100,000$ \\
\hline Arizona & 1 & General Manager & $10,001-100,000$ \\
\hline Arizona & 1 & Operations Manager & 100,001-1 million \\
\hline Arizona & 1 & Deputy Director & $100,001-1$ million \\
\hline California & 1 & Operations and Maintenance Director & $100,001-1$ million \\
\hline California & 1 & Operations Manager & $>1$ million \\
\hline California & $4^{a}$ & varying roles & $100,001-1$ million \\
\hline California & 1 & Assistant General Manager of Operations/Engineering & 100,001-1 million \\
\hline California & $6^{a}$ & varying roles & $>1$ million \\
\hline Colorado & 2 & Deputy Director of Public Works, Drinking Water Program Supervisor & 100,001-1 million \\
\hline Colorado & 2 & Project Manager, Senior Lead Operator & $10,001-100,000$ \\
\hline Connecticut & 1 & Supply Operations Manager & $100,001-1$ million \\
\hline Kentucky & 2 & $\begin{array}{l}\text { Vice President of Communications and Marketing, Manager of Distribution Water } \\
\text { Quality }\end{array}$ & $100,001-1$ million \\
\hline Massachusetts & 1 & Assistant Superintendent & $10,001-100,000$ \\
\hline Michigan & 1 & Water Quality Manager & $100,001-1$ million \\
\hline Michigan & 1 & Deputy Director of Water \& Wastewater & $100,001-1$ million \\
\hline New Jersey & 1 & Superintendent & 100,001-1 million \\
\hline Oregon & 1 & Water Quality Manager & $>1$ million \\
\hline Oregon & 2 & Director of Water Quality \& Treatment, Human Resources Manager & $100,001-1$ million \\
\hline Texas & 2 & Assistant Director, Supervising Engineer & $>1$ million \\
\hline Texas & 1 & Water Treatment and Compliance Manager & $10,001-100,000$ \\
\hline Texas & $4^{a}$ & varying roles & $>1$ million \\
\hline Texas & 1 & Building Manager & university campus $^{b}$ \\
\hline Utah & 1 & Water Quality \& Treatment Administrator & $100,001-1$ million \\
\hline Washington & 1 & Senior Environmental Specialist & $100,001-1$ million \\
\hline Washington & 1 & Senior Water Quality Engineer & $>1$ million \\
\hline Washington & $10^{a}$ & varying roles & $100,001-1$ million \\
\hline
\end{tabular}

Survey $^{27}$ with an additional category ( $>1$ million customers). Interviewees' experience ranged from 2 to 30 years.

We asked questions focused on understanding how utilities were impacted by the COVID-19 pandemic. We began interviews with broad questions about the pandemic to provoke thoughtful responses and then followed initial discussions with specific questions (e.g., about disinfectant residuals and the supply chain). Example interview questions are as follows: (1) In your experience, how has COVID-19 impacted your utility? (2) Do you think your customers are using water differently during shutdowns? (3) Did you have any supply chain issues? (4) Did the utility activate an emergency response plan?

2.2. Qualitative Analysis. All interviews were transcribed and then coded in a qualitative coding research database. Each excerpt was first categorized as a challenge/change or a response. We defined a challenge/change as obstacles faced by utilities to provide water services (e.g., lack of staff) or a change to the system (e.g., change in demand). A response was defined as anything a utility did to respond to or counteract challenges. Although the research questions provided a framework for analysis, we took an inductive analysis approach; excerpts were coded on the basis of emergent, general categories (Table 2) as opposed to predefined codes. These parent codes show broad thematic ideas, while excerpts also were coded by more specific ideas and are shown in the results (i.e., child codes). Coding was completed by two researchers, with excerpts reviewed by both researchers. In addition, the coding was validated through an intercoder reliability check $(\kappa$
$=0.86$ ), achieving a $\kappa$ value considered satisfactory for qualitative research. $^{24,28}$ This $\kappa$ value was calculated on the basis of 24 excerpts coded by both researchers.

2.3. Limitations. We used our data set to draw generalizable recommendations, despite sampling only a subset of U.S. utilities. Although this limits the implications that can be made, we conducted interviews until no new information emerged from subsequent interviews, ${ }^{26}$ indicating that the themes revealed in our study can be used to draw conclusions and recommend practical management strategies. In addition, we captured experiences from 28 utilities in varying geographic regions of the United States (see Table 1). Notably, the resulting frequencies do not necessarily indicate the intensity or prevalence of an issue. For example, a frequency of 10 excerpts for one challenge compared to two excerpts for another does not indicate that one issue was more challenging; rather, this finding captures awareness. In turn, instead of solely relying on frequency tables (Tables 3 and 4), we present how utilities experienced certain challenges or responded in certain ways through visualizations (Figures 1 and 2).

The COVID-19 pandemic was rapidly changing during the data collection period. Each geographic region experienced outbreaks at different times, and there were notable geographic variations in SDPs, enforcement, and compliance. It is important to note that this almost certainly impacts the changes observed by utilities. For instance, respondents' discussions may vary on the basis of the severity of an outbreak in their region at the interview time. We believe that the relatively short data collection period ( $\sim 2$ months) reduces 
the temporal aspect of this limitation but do not feel our data set was large enough to draw conclusions about how these differences may have influenced our results. More granular research is needed to better understand this and other consequences of SDPs.

\section{RESULTS AND DISCUSSION}

Although each utility has unique characteristics, some common challenges (Table 3 and Figure 1) and responses to such challenges (Table 4 and Figure 2) emerged from the data. Tables 3 and 4 show the frequencies of each code and the count of utilities that had excerpts coded to the theme. Figures 1 and 2 provide a visualization of what percent of utilities experienced certain challenges or performed certain actions in response. The figures also show what percent of utilities did not experience or did not mention the respective challenges or responses. Here we will discuss the larger thematic categories as outlined in Table 2.

3.1. Planning and Management. More than half of the coded excerpts were related to planning and management. Overall, utilities felt that SDPs dramatically changed the way utilities were managed. One interviewee said the stay-at-home orders "took [their] organization and flipped it on its head", while another mentioned that although the mission was unchanged-"to provide uninterrupted, reliable, sustainable utility services"- they had to do it under new circumstances. As expected, these changes came with challenges, specifically in planning, workforce management, and supply chain.

3.1.1. Planning. Utilities conveyed that a lack of pandemic planning hindered their ability to quickly respond; they had to first "learn how to respond to [a] pandemic". Approximately one-third (32\%) of utilities activated their emergency response plan, while other utilities (46\%) created or improved existing pandemic plans (see Figure 2 for information about the utilities that did not perform these actions or did not mention or know if the response was taken). Notably, only $39 \%$ of utilities noted that pandemic planning was incorporated in existing emergency response plans prior to COVID-19 (see Figure 1 for information about the utilities that did not experience this challenge or did not mention or know if they did). Many respondents noted that the COVID-19 pandemic allowed them to create improved or new pandemic plans and that they would be more prepared for future pandemics.

3.1.2. Workforce Management. Workforce management comprised $50 \%$ of challenges and $55 \%$ of responses coded under the planning and management theme. One interviewee said it was a "delicate balance of [continuing] to maintain operations and provide safe drinking water to people while protecting our personnel", and another called it a "labormanagement administrative nightmare". Utilities took various actions to ensure the safety of their staff (e.g., social distancing policies, shifts, and vehicle policies) and, as the potential risk varied, generally tailored their workforce policies to employees' roles (see Table 4). For instance, the risk of contracting COVID-19 when working will likely be lower for field staff compared to employees that work at a large treatment plant. At many utilities, field staff continued to work with adjustments such as using temporary facilities or taking their work vehicles home so they did not have to go into the office.

What was of utmost importance to utilities within the treatment plants was the safety of their operators. One utility observed that it would be traumatic to have just one of their operators unable to work. In turn, utilities took proactive steps 
Table 3. Select Portion of a Frequency Table of Challenges and Changes Faced by Utilities during the COVID-19 Pandemic (see the Supporting Information for the full table; relative frequency is the percent of all excerpts coded as challenges or changes)

\begin{tabular}{|c|c|c|c|c|c|}
\hline qualitative code & $\begin{array}{l}\text { no. of } \\
\text { utilities }\end{array}$ & $\begin{array}{l}\text { no. of responses } \\
\text { (relative } \\
\text { frequency) }\end{array}$ & qualitative code & $\begin{array}{l}\text { no. of } \\
\text { utilities }\end{array}$ & $\begin{array}{l}\text { no. of responses } \\
\text { (relative } \\
\text { frequency) }\end{array}$ \\
\hline \multirow{2}{*}{$\begin{array}{l}\text { excerpts about COVID-related challenges or } \\
\text { changes }\end{array}$} & \multirow[t]{2}{*}{28} & \multirow[t]{2}{*}{$410(100.0 \%)$} & increased demand & 12 & $18(4.4 \%)$ \\
\hline & & & $\begin{array}{l}\text { residential increase offset commercial } \\
\text { decrease }\end{array}$ & 7 & $7(1.7 \%)$ \\
\hline \multirow{3}{*}{$\begin{array}{l}\text { planning and management } \\
\text { institutional collaboration (e.g., conferences } \\
\text { canceled, working with government/unions) }\end{array}$} & \multirow{3}{*}{$\begin{array}{r}28 \\
5\end{array}$} & \multirow{3}{*}{$\begin{aligned} 205 & (50.0 \%) \\
8 & (2.0 \%)\end{aligned}$} & decrease in demands at universities or & 6 & $8(2.0 \%)$ \\
\hline & & & similar to holiday breaks & & \\
\hline & & & overall system demand & 13 & $22(5.4 \%)$ \\
\hline \multirow{2}{*}{$\begin{array}{l}\text { internal communication (e.g., loss of adjacency, } \\
\text { between shift changes) }\end{array}$} & \multirow[t]{2}{*}{10} & \multirow[t]{2}{*}{$16(3.9 \%)$} & decrease in overall demand & 10 & $15(3.7 \%)$ \\
\hline & & & increase in overall demand & 3 & $7(1.7 \%)$ \\
\hline \multirow{3}{*}{$\begin{array}{l}\text { planning } \\
\text { adapting and planning to ensure continuity } \\
\text { of services }\end{array}$} & 12 & $19(4.6 \%)$ & \multirow{2}{*}{$\begin{array}{l}\text { continuing maintenance (e.g., delayed response, } \\
\text { with social distancing) }\end{array}$} & \multirow[t]{2}{*}{3} & \multirow[t]{2}{*}{$3(0.7 \%)$} \\
\hline & 4 & $5(1.2 \%)$ & & & \\
\hline & \multirow{3}{*}{9} & \multirow{3}{*}{$11(2.7 \%)$} & decrease in pipe breaks & 2 & $3(0.7 \%)$ \\
\hline \multirow{2}{*}{$\begin{array}{l}\text { lack of pandemic preparation (e.g., public } \\
\text { health knowledge, pandemic plans) }\end{array}$} & & & water quality & 6 & $12(2.9 \%)$ \\
\hline & & & disinfectant residuals & 4 & $6(1.5 \%)$ \\
\hline $\begin{array}{l}\text { managing a prolonged event vs a discrete } \\
\text { disaster }\end{array}$ & 3 & $3(0.7 \%)$ & higher than normal residuals & 1 & $1(0.2 \%)$ \\
\hline supply chain & 27 & $60(14.6 \%)$ & low residuals & 3 & $5(1.2 \%)$ \\
\hline $\begin{array}{l}\text { difficulty procuring or worry about routine } \\
\text { supplies (e.g., chemicals, valves) }\end{array}$ & 16 & $30(7.3 \%)$ & managing water quality & 4 & $6(1.5 \%)$ \\
\hline \multirow{2}{*}{$\begin{array}{l}\text { difficulty procuring personal protective } \\
\text { equipment (PPE) or sanitation materials }\end{array}$} & \multirow[t]{2}{*}{20} & \multirow[t]{2}{*}{$30(7.3 \%)$} & finances & 21 & $58(14.1 \%)$ \\
\hline & & & billing (e.g., customer payments, rates, revenue) & 20 & $54(13.2 \%)$ \\
\hline workforce-related & 25 & $102(24.9 \%)$ & billing cycle altered due to challenges & 1 & $1(0.2 \%)$ \\
\hline lack of staff during pandemic (e.g., family & 7 & $12(2.9 \%)$ & reading meters & & \\
\hline leave, retiring early) & & & policies about no shut-offs or rate increases & 7 & $7(1.7 \%)$ \\
\hline personnel management & 21 & $58(14.1 \%)$ & led to challenges & & \\
\hline ensuring safety of operations staff & 4 & $8(2.0 \%)$ & increase in delinquencies or enrollment in & 13 & $25(6.1 \%)$ \\
\hline providing emotional support & 1 & $2(0.5 \%)$ & customer assistance programs & & \\
\hline implementing social distancing and & 15 & $25(6.1 \%)$ & revenue change & 14 & $21(5.1 \%)$ \\
\hline sanitation protocols & & & decrease in revenue & 12 & $19(4.6 \%)$ \\
\hline increased workload for managers & 6 & $8(2.0 \%)$ & increase in revenue & 2 & $2(0.5 \%)$ \\
\hline training new staff & 3 & $3(0.7 \%)$ & change in spending or financial capacity (e.g., & 4 & $4(1.0 \%)$ \\
\hline $\begin{array}{l}\text { transitioning technology to work from } \\
\text { home (e.g., IT issues) }\end{array}$ & 10 & $12(2.9 \%)$ & negative financial impacts, delayed budget) & & \\
\hline adjusting workflow (e.g., delays, challenges & 3 & $3(0.7 \%)$ & community-related & 14 & $25(6.1 \%)$ \\
\hline working from home) & & & adapting outreach and communication strategies & 5 & $8(2.0 \%)$ \\
\hline workforce's perceptions and attitudes (e.g., & 11 & $29(7.1 \%)$ & (e.g., virtual issues, delays responding) & & \\
\hline morale, different views, resistance to & & & customer calls or complaints & 9 & $14(3.4 \%)$ \\
\hline & & & $\begin{array}{l}\text { decrease in customer calls (e.g., because no } \\
\text { shut-offs) }\end{array}$ & 4 & $6(1.5 \%)$ \\
\hline technical system & 25 & $109(26.6 \%)$ & increase in customer complaints and & 6 & $8(2.0 \%)$ \\
\hline demand and water use & 24 & $91(22.2 \%)$ & concerns (e.g., aesthetics, worry about water & & \\
\hline change in demand (total, patterns) based on & 20 & $69(16.8 \%)$ & safety) & & \\
\hline user type & & & change in public use of utilities' watershed (e.g., & 3 & $3(0.7 \%)$ \\
\hline commercial & 14 & $18(4.4 \%)$ & increase, more trespassing) & & \\
\hline decrease in demand & 13 & $17(4.1 \%)$ & & & \\
\hline slight increase in demand & 1 & $1(0.2 \%)$ & regulatory requirements and testing & 9 & $13(3.2 \%)$ \\
\hline decrease in industrial demand & 6 & $8(2.0 \%)$ & challenge adhering to state shutdown guidelines & 3 & $3(0.7 \%)$ \\
\hline $\begin{array}{l}\text { decrease in outdoor entertainment (e.g., } \\
\text { golf course, water park) }\end{array}$ & 2 & $2(0.5 \%)$ & challenge to perform testing (e.g., because in & 8 & $10(2.4 \%)$ \\
\hline residential & 15 & $26(6.3 \%)$ & & & \\
\hline $\begin{array}{l}\text { change in residential demand curve } \\
\text { (e.g., peaks reduced, morning peak } \\
\text { delayed) }\end{array}$ & 7 & $8(2.0 \%)$ & & & \\
\hline
\end{tabular}

such as making treatment plants restricted access, putting operators on shifts, and setting up secondary control stations. Notably, the size of the utility and the design of the water treatment plant impact the amount of contact operators have with others. For instance, one utility that serves fewer than 100,000 people had limited workforce challenges at their treatment plant because it was not necessary to staff the treatment plant 24/7. The challenge of protecting operators presents a significant vulnerability in water systems as there are often few people trained for each system. Despite recent technological innovations, operators are still critical to the water system due to their supervisory role. ${ }^{12}$ With an aging workforce and a limited pool of qualified talent, water utilities were, even prior to the pandemic, struggling with a lack of staff. $^{29}$ This was exacerbated during the pandemic as some staff retired early, were unable to work without childcare, or decided to not work due to preexisting conditions that put them at increased risk if they were to contract COVID-19. 
Table 4. Select Portion of a Frequency Table of Utilities' Response to the COVID-19 Pandemic (see the Supporting Information for the full table; relative frequency is the percent out of all response excerpts)

\begin{tabular}{|c|c|c|}
\hline qualitative code & $\begin{array}{l}\text { no. of } \\
\text { utilities }\end{array}$ & $\begin{array}{l}\text { no. of responses } \\
\text { (relative } \\
\text { frequency) }\end{array}$ \\
\hline excerpts about utilities' response to COVID-19 & 28 & $470(100.0 \%)$ \\
\hline planning and management & 28 & $331(70.4 \%)$ \\
\hline $\begin{array}{l}\text { change in capital projects (e.g., delayed, } \\
\text { increased during shutdown) }\end{array}$ & 14 & $17(3.6 \%)$ \\
\hline $\begin{array}{l}\text { increase in institutional collaboration (e.g., } \\
\text { federal agencies, other utilities) }\end{array}$ & 13 & $19(4.0 \%)$ \\
\hline $\begin{array}{l}\text { new internal communication plans (e.g., } \\
\text { regular updates, technology, focus on morale) }\end{array}$ & 12 & $25(5.3 \%)$ \\
\hline planning & 23 & $47(10.0 \%)$ \\
\hline $\begin{array}{l}\text { activated/used emergency response plan or } \\
\text { created/improved a pandemic plan }\end{array}$ & 20 & $28(6.0 \%)$ \\
\hline $\begin{array}{l}\text { other pandemic planning (e.g., front-end } \\
\text { planning, for a possible recession) }\end{array}$ & 14 & $19(4.0 \%)$ \\
\hline supply chain & 22 & $42(8.9 \%)$ \\
\hline $\begin{array}{l}\text { became a priority customer to supplier or } \\
\text { found backup supplier }\end{array}$ & 4 & $4(0.9 \%)$ \\
\hline $\begin{array}{l}\text { innovative actions to meet supply chain } \\
\text { issues (e.g., in-house manufacturing) }\end{array}$ & 6 & $8(1.7 \%)$ \\
\hline ordered extra materials & 10 & $13(2.8 \%)$ \\
\hline $\begin{array}{l}\text { reached out to suppliers to ensure } \\
\text { materials }\end{array}$ & 13 & $14(3.0 \%)$ \\
\hline used stocked masks & 3 & $3(0.6 \%)$ \\
\hline workforce-related & 28 & $181(38.5 \%)$ \\
\hline $\begin{array}{l}\text { general shift changes or furloughs for all } \\
\text { staff }\end{array}$ & 7 & $8(1.7 \%)$ \\
\hline $\begin{array}{l}\text { most or all customer service staff work } \\
\text { from home }\end{array}$ & 4 & $5(1.1 \%)$ \\
\hline $\begin{array}{l}\text { change in field staff's workflow (e.g., shifts, } \\
\text { temporary facilities, no time in the office) }\end{array}$ & 17 & $34(7.2 \%)$ \\
\hline $\begin{array}{l}\text { change in lab staffs workflow (e.g., } \\
\text { increased hours, contactless sample } \\
\text { deliveries) }\end{array}$ & 5 & $6(1.3 \%)$ \\
\hline $\begin{array}{l}\text { change in operation staff's workflow (e.g., } \\
\text { restricted access to plants, shifts) }\end{array}$ & 22 & $35(7.4 \%)$ \\
\hline $\begin{array}{l}\text { change in professional/office staff's } \\
\text { workflow (e.g., work from home) }\end{array}$ & 21 & $39(8.3 \%)$ \\
\hline $\begin{array}{l}\text { new workplace policies (e.g., social } \\
\text { distancing, cleaning, leave policies, vehicle } \\
\text { rules) }\end{array}$ & 22 & $54(11.5 \%)$ \\
\hline
\end{tabular}

\begin{tabular}{|c|c|c|}
\hline qualitative code & $\begin{array}{c}\text { no. of } \\
\text { utilities }\end{array}$ & $\begin{array}{l}\text { no. of responses } \\
\text { (relative } \\
\text { frequency) }\end{array}$ \\
\hline technical system & 15 & $32(6.8 \%)$ \\
\hline $\begin{array}{l}\text { noncritical maintenance deferred, slowed, or } \\
\text { stopped at one point }\end{array}$ & 9 & $14(3.0 \%)$ \\
\hline $\begin{array}{l}\text { contracted cleaning services for bathrooms } \\
\text { around water sources }\end{array}$ & 1 & $1(0.2 \%)$ \\
\hline $\begin{array}{l}\text { changed physical infrastructure operations } \\
\text { (e.g., shut down plant, adjusted tanks) }\end{array}$ & 1 & $3(0.6 \%)$ \\
\hline $\begin{array}{l}\text { change in water quality management (e.g., } \\
\text { chemical dosing or flushing) }\end{array}$ & 8 & $15(3.2 \%)$ \\
\hline finances & 21 & $46(9.8 \%)$ \\
\hline $\begin{array}{l}\text { billing (e.g., customer payments, rates, } \\
\text { revenue) }\end{array}$ & 16 & 23 (4.9\%) \\
\hline $\begin{array}{l}\text { expansion of customer assistance programs } \\
\text { (e.g., payment plans, small businesses) }\end{array}$ & 13 & $18(3.8 \%)$ \\
\hline $\begin{array}{l}\text { rate changes enacted or postponed (e.g., } \\
\text { increase rates, postponed increase) }\end{array}$ & 4 & $5(1.1 \%)$ \\
\hline financing or funding & 10 & $11(2.3 \%)$ \\
\hline $\begin{array}{l}\text { adjusted loans or bonds (e.g., delayed } \\
\text { applying, refinanced) }\end{array}$ & 3 & $3(0.6 \%)$ \\
\hline $\begin{array}{l}\text { plan to apply for federal funds or tracked } \\
\text { spending in case }\end{array}$ & 7 & $8(1.7 \%)$ \\
\hline spending or financial capacity & 6 & $12(2.6 \%)$ \\
\hline hiring freeze or reduction in hiring & 4 & $5(1.1 \%)$ \\
\hline $\begin{array}{l}\text { increase in expenditures (due to social } \\
\text { distancing policies or expected budget cut) }\end{array}$ & 3 & $3(0.6 \%)$ \\
\hline $\begin{array}{l}\text { operations and maintenance spending } \\
\text { reductions }\end{array}$ & 2 & $4(0.9 \%)$ \\
\hline community-related & 20 & $48(10.2 \%)$ \\
\hline $\begin{array}{l}\text { change in customer service operations (e.g., } \\
\text { reduced hours, in-person service suspended) }\end{array}$ & 7 & $9(1.9 \%)$ \\
\hline $\begin{array}{l}\text { adapted outreach strategies (e.g., building } \\
\text { flushing protocols, safety information, virtual) }\end{array}$ & 19 & $38(8.1 \%)$ \\
\hline regulatory requirements and testing & 7 & $12(2.6 \%)$ \\
\hline $\begin{array}{l}\text { changed location of monitoring sites or added } \\
\text { additional sites (e.g., public spaces) }\end{array}$ & 6 & $9(1.9 \%)$ \\
\hline planned for a reduction in or reduced & 2 & $3(0.6 \%)$ \\
\hline
\end{tabular}

nonregulatory testing

Managers mentioned that their jobs drastically changed as they developed and implemented SDPs. One interviewee said that "the pandemic was another job packed on top of [their] job”. Another described adapting to the latest shelter-in-place orders as an "exhausting exercise" saying that a "new one comes out every week [and we have to interpret it], which is not always easy". With limited pandemic planning in the water sector, managers struggled to quickly adapt. Utilities noted that, as they created responses to SDPs, they used best practices from other organizations (e.g., Water Research Foundation and American Water Works Association) and existing examples from other utilities. This could be expected based on research focused on knowledge-sharing connections and time savings. ${ }^{30}$ In addition, interviewees mentioned that managing their workforce during a pandemic was outside of their knowledge and training. For instance, one respondent said, "I didn't have training in providing psychological support to 150 people. All of a sudden I'm being called to do that, to motivate them, to provide basically emotional support for them to stay motivated, not to lose focus, and not to just take care of themselves but take care of their family."

In addition, managing staff became more challenging because there was a lack of adjacency-no hallway conversations or face-to-face meetings. In turn, utilities used technology for communication and implemented new internal communication strategies (e.g., online COVID-19 resources and frequent check-ins with employees for emotional support).

3.1.3. Supply Chain. Utilities faced an array of supply chain issues, from routine supplies (e.g., disinfectant chemicals and testing materials) to personal protective equipment (PPE). Of the utilities surveyed, $71 \%$ experienced issues procuring the needed PPE and sanitation materials to operate safely (see Figure 1 for information about the utilities that did not experience this challenge or did not mention or know if they did). Interestingly, many utilities responded creatively to this challenge. For instance, utilities made certain resources in house (e.g., hand sanitizer) and one utility even changed their sampling techniques due to a shortage of alcohol. To clean the 

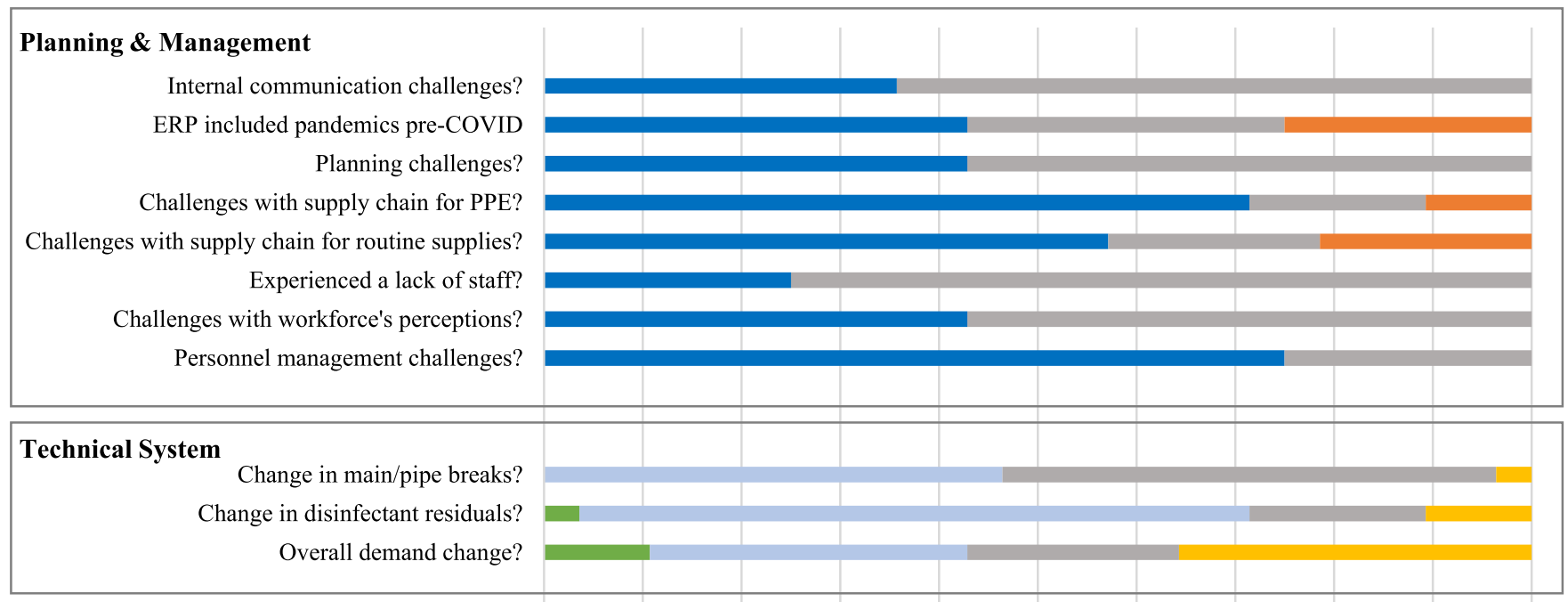

\begin{tabular}{|r|r|r|r|r|r|}
\hline Finances & & & \\
Increase in delinquent accounts? \\
Revenue change?
\end{tabular}

Community-Related

Change in customer calls?

Regulatory Requirements \& Testing

Challenges to perform regulatory sampling?

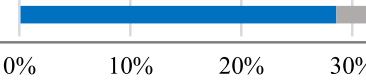

Percent of Responding Utilities

Increase $\square$ No Change $\square$ Decrease $\square$ Yes $\square$ Unknown or not mentioned $\square$ No

*ERP $=$ emergency response plan; $\mathrm{PPE}=$ personal protective equipment

Figure 1. Challenges and changes experienced by responding utilities (not inclusive of all codes; see the Supporting Information for the full frequency table).

taps they were testing, they relied on flaming the spigot, a method commonly used in the 1990s.

Even for routine supplies, there were supply chain issues. Utilities were concerned about shortages of multiple chemicals and resources (e.g., chlorine, carbon dioxide, oxygen, sodium hypochlorite, and alum). Despite the concern, most utilities were able to ensure access to these resources by reaching out to suppliers, ordering early, or becoming a priority customer (by paying a premium or working with the government). Notably, utilities did experience delays receiving materials, especially from abroad. One interviewee, for instance, said, "We did [order] some specialty valves from Italy. Suffice to say, we haven't got them in yet." Overall, utilities were able to cope with these supply chain challenges, but in the event of future disasters, these vulnerabilities could be reduced by improved planning. For instance, utilities might proactively discuss becoming a priority customer with their suppliers.

3.1.4. Capital Projects. Lastly, it is important to note that utilities had to change their plans for capital projects. Interestingly, one utility was able to accelerate a capital project at a water treatment plant because it was shut down due to decreased system demand. Most other utilities experienced the opposite-12 utilities had to delay or scale back projects. This was due to financial constraints for five utilities, organizational workforce SDPs for three utilities, supply chain delays for one utility, and administrative delays due to increased workload for another (and two utilities did not explicitly describe why). Respondents pointed out that these changes to capital projects could create future issues because there is a critical need to update aging infrastructure and many projects were already overdue. One respondent said that a capital project delay at the treatment plant would lead to future water quality issues and that they could not "keep slapping Band-Aids on something. At a certain point, it's going to fail, and who knows when it [will]." Results focused on management and planning show that COVID-19 exacerbated existing, widespread water infrastructure issues such as aging infrastructure and a shortage of qualified workers. It is worth noting that the pandemic might accelerate the impacts of these challenges (e.g., earlier retirements than expected and delaying planned capital projects).

3.2. Technical System. 3.2.1. Demand, Water Use, and Pipe Breaks. At many utilities, SDPs altered the spatial distribution of demand, demand patterns, and overall system demand. In fact, all but four utilities mentioned some change or challenge associated with water use (see demand and water use in Table 3). In terms of demand by customer class, $43 \%$ of utilities mentioned an increase in residential demand, $46 \%$ mentioned a decrease in commercial demand, and $21 \%$ mentioned a decrease in industrial demand (see Figure 1 for information about the utilities that did not experience these changes or did not mention or know if they did). Interestingly, 


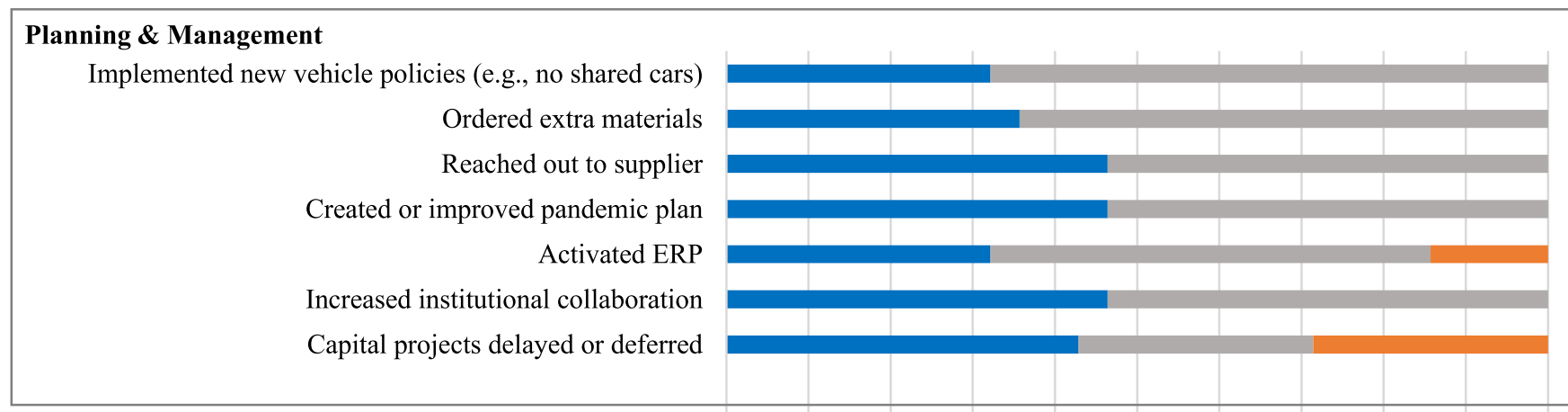

Technical System

Adjustment to flushing protocols

Deferred non-critical maintenance

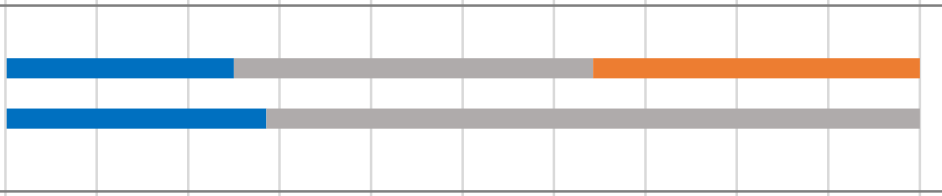

\begin{tabular}{|l|l|l|l|l|l|l|l|l|l|}
\hline Finances & & & \\
\hline
\end{tabular}

\section{Community-Related}

Expanded customer relief (aside from federal requirements)

Increased community outreach

$$
\begin{aligned}
& \begin{array}{lllllllllll}
0 \% & 10 \% & 20 \% & 30 \% & 40 \% & 50 \% & 60 \% & 70 \% & 80 \% & 90 \% & 100 \%
\end{array} \\
& \text { Percent of Responding Utilities }
\end{aligned}
$$

- Yes Unknown or not mentioned $\quad$ No

${ }^{*} \mathrm{ERP}=$ emergency response plan; $\mathrm{PPE}=$ personal protective equipment

Figure 2. Utilities' response to the COVID-19 pandemic (not inclusive of all codes; see the Supporting Information for the full frequency table).

some utilities reported that there were no changes to demand for industrial customers because operations continued at critical services (e.g., transportation and energy). For the total demand change (see overall demand change in Figure 1 for a detailed breakdown of utilities' responses to this question), most utilities saw a decrease $(36 \%)$ or no change in demand (32\%) while $11 \%$ saw an increase in demand. The magnitude of demand changes varied by utility, with one utility experiencing $70 \%$ less demand than normal. Notably, the system demand was related to utilities' customer composition; largely residential utilities tended to see an increase in demand, while utilities that served large commercial areas or industrial customers saw a decrease in demand. Many utilities that saw no change in overall demand attributed it to the fact that the increase in residential demand offset decreases in commercial demand (i.e., "a shift between rate classes").

Practically, pandemic planning should take into account the composition of a utility's customers to predict potential demand changes. When responding to future pandemics, utilities should look back on experiences during the COVID-19 pandemic. Nevertheless, it is important for managers to realize that future changes in a utility's customer base would also change demands during a pandemic. In turn, population predictions (i.e., expected demand change) from planning procedures should be incorporated into pandemic plans.

In addition to system demand changes, some utilities (25\%) mentioned a change in their demand curves for residential customers (i.e., people were using water differently during the pandemic). Note that the interview question was asked as "Were your customers using water differently?", so the other $75 \%$ of utilities either did not mention changes in residential demand curves, did not know, or said there were no changes. Three utilities mentioned that the morning peak was delayed, likely because people working from home were no longer commuting. One interviewee observed a noticeable change in demand curves, saying "everything looks like a weekend". These temporal demand changes likely increased the risk of operational issues, but most utilities did not experience notable problems. For instance, 32\% of utilities noted that there were no pressure issues; $46 \%$ said that there was not an increase in the number of system failures (e.g., pipe breaks), and $25 \%$ did not notice changes in tank turnover (see Figure 1 for information about the utilities that did not experience these challenges or did not mention or know if they did). Conversely, one utility mentioned that their "main break rate went down dramatically, right as the shelter orders were taking effect, and [they] didn't know why". The interviewee presented two theories as to why this reduction in the number of breaks occurred: (1) decreased traffic (i.e., less road vibration) and (2) fewer transient pressure spikes in the system due to industrial customers shutting down. This utility noted that transient pressure spikes were the lowest when SDPs were the most stringent. This experience reveals that pandemic-induced demand changes might have unexpected positive consequences on the water system's operations (i.e., the system behaves differently than expected).

3.2.2. Water Quality and Maintenance. The water age in the distribution system is inherently connected to changes in demand, leading to possible water quality challenges when demand declines. Notably, $64 \%$ of utilities in our analysis did not see a change in disinfectant residuals throughout the distribution system (see Figure 1 for information about the 
utilities that did experience a change in residuals or did not mention or know if they did). Despite demand changes, most utilities did not observe negative water quality consequences and were able to continue to provide water quality at prepandemic levels, revealing a sign of resilience within water systems. Of the utilities that did see changes to disinfectant residuals, only three (one a university campus) mentioned lower-than-usual residuals. Two of the three interviewees that noted low residuals conducted sampling prior to flushing in buildings, a fact that reinforces the importance of flushing premise plumbing during pandemics. Most utilities that noticed low residuals increased system flushing in problematic areas, while only one utility noted that they preemptively increased flushing due to demand changes (e.g., in commercial areas that saw a decrease in water demand). On the contrary, $18 \%$ of utilities noted that they postponed or stopped flushing due to staffing constraints (see Figure 2 for information about the utilities that did not change protocols or did not mention or know if the response was taken). COVID-related workforce challenges (i.e., limited staff) directly impacted utilities' ability to perform system flushing as they had to prioritize critical work. Staffing shortages also caused utilities to adjust their maintenance strategies. Nearly one-third (32\%) of utilities deferred noncritical maintenance such as replacing meters at customers' homes, preventative maintenance, or fixing small leaks, while all other utilities were unsure or did not mention deferring maintenance. Similar to the future implications of delaying capital projects, delayed maintenance could cause future infrastructure issues.

3.3. Finances. The COVID-19 pandemic changed utilities' financial capacities and spending. Forty-three percent of utilities interviewed experienced revenue decreases. Of these, six experienced a decrease in overall demand and six said that demand had not noticeably changed. Many state and local governments implemented regulations ensuring access to water services despite users' ability to pay (e.g., no water shutoffs during the pandemic and loan forgiveness), contributing to revenue decreases. Of utilities in our sample, 46\% (13 utilities) mentioned an increase in late payments or delinquent accounts and seven of these explicitly mentioned a revenue decrease (see Figure 1 for a detailed breakdown of information about delinquent accounts). In turn, we can infer that both late payments and demand decreases contributed to revenue loss. The change in revenue varied among utilities, with some utilities seeing dramatic decreases. For instance, one interviewee noted that their utility's revenue was down $70 \%$ and that, despite cost reductions, it was a major concern due to fixed costs. Another interviewee noted that their revenue numbers were "horrible". This unexpected revenue decrease led to management and operational challenges. For instance, many of the delays in capital projects (see section 3.1.4) and the reduction in maintenance (see section 3.2.2) were due to this decrease in financial capacity. Additionally, three utilities mentioned that they were unable to or discouraged from increasing water rates as planned, leading to long-term challenges after the pandemic. As one interviewee stated, "A couple of big challenges that we're facing is that we are in the process of developing our budget for the next biennium. And with that in mind, and pressure from board and council to look into zero rate adjustments ... we still feel the inflationary costs, too. So that's something to consider if we do have zero rate adjustments, it might take us, say six years-that's what we're modeling - to catch back up. And so in the long run, it's probably not to the benefit of the utility, or our customers."

In response to COVID-19, utilities accrued new expenses associated with SDPs. For example, one utility rented extra vehicles to maintain personnel safety and another lost money while sequestering employees. Many utilities accrued expenses when they expanded their customer assistance programs due to the pandemic (e.g., expanding the threshold to be eligible for programs). One utility even created an assistance program for small businesses. In summary, many utilities were experiencing decreased revenue and increased operational expenses due to the pandemic. Although $25 \%$ of utilities reported that they planned to apply for federal funding, respondents generally did not know of a clear opportunity for funding to cope with pandemic-induced financial challenges, revealing a gap in state and federal legislation ( $77 \%$ of utilities did not know about or mention federal funding).

3.4. Community-Related. The pandemic also altered the way in which utilities communicate and interact with residents. For instance, many utilities closed in-person customer service or changed hours of operation. One utility was able to provide drive-through customer service for customers to pay their bills. SDPs came with community-related challenges such as increased response time and communication challenges. Two-thirds of utilities adapted their outreach strategies, such as creating outreach materials for water safety and flushing protocols. In addition, the COVID-19 pandemic forced water utilities to rely on technology for public communication and outreach (e.g., virtual meetings and increased use of social media). One utility said that these technological strategies actually improved their communication with the public: "Our communication with the public had changed, really for the better though. It increased the amount of communication and the methods that we used. We used to just put up signs, metal signs, in the neighborhoods, and have a little blurb on our website, but we started doing almost a reverse 911 type callout to customers. And a lot more social media presence with regard to all that, just so they know what's going on and why we are doing it, so they're not concerned."

After the COVID-19 pandemic, utilities expressed that they would likely continue new outreach strategies to improve their customers' experiences. It is important to note that customer service and communication shifting online led to possible equity issues for customers without access to the Internet. For instance, customers might face barriers to pay their bill or fail to receive communications from the utility when the main medium is online (e.g., email and social media). If utilities decide to make this technological shift permanent, they need to come up with provisions to ensure equity and accessibility of information.

Despite communication efforts, five utilities (18\%) did see an increase in the number of customer complaints or calls (see Figure 1 for a breakdown of utilities' changes in customer calls). These calls were for various reasons (e.g., aesthetic complaints and questions about water safety). Three of these utilities speculated that the increase in the number of complaints was due to people being at home more and, in turn, being more sensitive to water aesthetics or concerned about their tap water. On the contrary, four utilities reported a decrease in the number of customer calls, likely due to the policy of no water shutoffs (i.e., customers were less concerned about their bills). 
3.5. Regulatory Requirements and Testing. Water utilities must adhere to water quality standards that are in place to ensure public safety. Although the minimum standards are specified by the federal Primary Drinking Water Regulations, ${ }^{31}$ states may set and enforce more stringent standards. To show compliance, water utilities must perform regular water quality testing at the treatment plant and in the distribution system. During the COVID-19 pandemic, it became more of a challenge to perform these required tests (e.g., for disinfectants and disinfection byproducts, lead and copper, and coliforms). Specifically, 29\% of utilities mentioned that they struggled to perform testing due to issues such as lack of staff, supply chain challenges, and inability to sample at customers' homes (see Figure 1 for information about the utilities that did not experience this challenge or did not mention or know if they did). In response to this challenge, utilities changed the location of sample sites or added backup sites in case of complications. One utility continued to sample in customers' homes but, to maintain social distancing, allowed the residents to collect the samples. Notably, two utilities reduced nonregulatory testing, such as water quality monitoring in reservoirs or groundwater sources.

\section{STUDY IMPLICATIONS}

This section outlines the implications for policy (i.e., suggestions to improve water utilities' resilience to future pandemics) and practice (i.e., utility planning recommendations). Similar to findings about natural disasters, ${ }^{32}$ we discovered that the COVID-19 pandemic amplified existing challenges. When interviewees discussed challenges faced during the pandemic, they often pointed to the fact that these issues existed before the pandemic. For instance, one interviewee said, "I really think it's just the concerns that we [utility] are already dealing with are sort of magnified by the coronavirus." Some of these challenges were utility-specific, while other challenges were consistent between utilities, emerging as prevalent, systematic water infrastructure issues in the United States. For instance, aging infrastructure and a lack of qualified staff were widely known challenges before the pandemic. $^{29,33}$ Also, operators were identified as points of vulnerability as respondents mentioned that operational issues would arise with even one operator being unable to work. These challenges were amplified during the COVID-19 pandemic, and the repercussions of not addressing these challenges could also be intensified or occur earlier. For instance, delaying capital projects during the pandemic will only exacerbate the issue of aging infrastructure. Delays compounded with financial issues at utilities (e.g., revenue decrease and delayed rate increases) will make it challenging for utilities to remain on the same capital project schedule. In turn, the water system as a whole will be less resilient to future disasters. In general, this finding further supports the urgent need for federal and state policy to address gaps in infrastructure funding. With regard to consequences from this pandemic, it would be beneficial to provide funding for operational expenses and revenue deficits that occurred. This would enable utilities to continue funding capital projects and infrastructure upgrades as the COVID-19 pandemic continues and for future pandemics. In addition, we believe this funding could be used to provide more equitable water sector services by ensuring that needed capital projects are carried out in underserved areas (we recommend including equity metrics in project decision making as discussed by Jones and
Armanios $^{34}$ ). Such funding could also enable utilities to extend affordability programs during the pandemic-induced economic crisis.

From a planning perspective, our results indicate that there is a widespread need to integrate pandemic planning into the existing long-term planning literature. From these short-term demand changes occurring during the COVID-19 pandemic, we can learn how to better manage long-term population dynamics due to population decline (e.g., revenue decrease and underutilized infrastructure ${ }^{15,19,20}$ ) or gentrification (e.g., the demand patterns change due to new sociodemographics). In turn, the results show that pandemic planning should be integrated into existing population planning at water utilities. In addition, future studies should focus on incorporating pandemic planning into disaster-specific research to capture multiple hazards.

\section{CONCLUSIONS}

Social distancing policies enacted due to the COVID-19 pandemic led to a sudden spatial and temporal shift in drinking water demand. The utilities we interviewed were able to meet this immense challenge and protect water quality and operations. Still, despite this resounding success and although utilities plan regularly for more typical population changes, most had no advance plans that would have better enabled them to respond to this scale of modification in operations. In addition, during the utilities' response, they were tasked with implementing SDPs within their workforce and were impacted by other repercussions of the pandemic (e.g., supply chain and financial concerns). In the study presented here, we identified how utilities were challenged during SDPs and responded to ensure the continuous provision of drinking water. We performed 30 semistructured interviews and focus groups with more than 50 utility employees. The data set included input from 28 utilities and was qualitatively coded on the basis of emergent themes. Before the COVID-19 pandemic, there was little research focused on water utilities' operation during pandemics. Our study contributes to this gap in the literature and provides practical planning recommendations to utilities. Findings also highlight the need for funding and research to ensure resilient water infrastructure systems that are capable of responding to unexpected stresses, such as pandemics, without sacrificing sustainability and public health.

\section{ASSOCIATED CONTENT}

\section{SI Supporting Information}

The Supporting Information is available free of charge at https://pubs.acs.org/doi/10.1021/acsestwater.0c00229.

Full frequency tables of challenges faced by utilities and utilities' responses to the COVID-19 pandemic, which are extended versions of Tables 3 and 4 (PDF)

\section{AUTHOR INFORMATION}

\section{Corresponding Author}

Kasey M. Faust - Civil, Architectural and Environmental Engineering, The University of Texas at Austin, Austin, Texas 78751, United States; 이이.orcid/0000-0001-7986-4757; Email: faustk@utexas.edu 


\section{Authors}

Lauryn A. Spearing - Civil, Architectural and Environmental Engineering, The University of Texas at Austin, Austin, Texas 78751, United States

Nathalie Thelemaque - Civil and Environmental Engineering, The University of Washington, Seattle, Washington 98195, United States

Jessica A. Kaminsky - Civil and Environmental Engineering, The University of Washington, Seattle, Washington 98195, United States; (1) orcid.org/0000-0002-1340-7913

Lynn E. Katz - Civil, Architectural and Environmental Engineering, The University of Texas at Austin, Austin, Texas 78751, United States

Kerry A. Kinney - Civil, Architectural and Environmental Engineering, The University of Texas at Austin, Austin, Texas 78751, United States

Mary Jo Kirisits - Civil, Architectural and Environmental Engineering, The University of Texas at Austin, Austin, Texas 78751, United States

Lina Sela - Civil, Architectural and Environmental Engineering, The University of Texas at Austin, Austin, Texas 78751, United States; 이이이.org/0000-0002-5834-8451

Complete contact information is available at:

https://pubs.acs.org/10.1021/acsestwater.0c00229

\section{Author Contributions}

Conceptualization and design: L.A.S., J.A.K., and K.F. Data collection: J.A.K., K.F., and L.A.S. Data coding and analysis: L.A.S. and N.T. Coding validation: L.A.S., N.T., J.A.K., and K.F. Writing of the original draft: L.A.S. Review and editing: all authors. Supervision: K.F.

\section{Notes}

The authors declare no competing financial interest.

\section{ACKNOWLEDGMENTS}

This material is based upon work supported by the National Science Foundation under Grant 2032434/2032429 and the National Science Foundation Graduate Research Fellowship Program under Grant DGE-1610403.

\section{REFERENCES}

(1) American Water Works Association. COVID-19 Utility and Water Sector Organization Impact Survey (April 17-22, 2020). 2020.

(2) National Research Council. Improving the Nation's Water Security: Opportunities for Research; National Academies Press: Washington, DC, 2007.

(3) The Preparedness Emergency Response and Recovery Critical Infrastructure Partnership Advisory Council (CIPAC) Working Group. All-Hazard Consequence Management Planning for the Water Sector. 2009.

(4) Van Atta, P.; Newsad, R. Water System Preparedness and Best Practices for Pandemic Influenza. J. - Am. Water Works Assoc. 2009, 101 (1), 40-53.

(5) Neal, M. J. COVID-19 and Water Resources Management: Reframing Our Priorities as a Water Sector. Water Int. 2020, 45, 435.

(6) Sowby, R. B. Emergency Preparedness after COVID-19: A Review of Policy Statements in the U.S. Water Sector. Util. Policy 2020, 64 (April), 101058.

(7) Poch, M.; Garrido-Baserba, M.; Corominas, L.; PerellóMoragues, A.; Monclús, H.; Cermerón-Romero, M.; Melitas, N.; Jiang, S. C.; Rosso, D. When the Fourth Water and Digital Revolution Encountered COVID-19. Sci. Total Environ. 2020, 744, 140980.

(8) Sivakumar, B. COVID-19 and Water. Stoch. Environ. Res. Risk Assess. 2020, 6, 10-13.
(9) Cotterill, S.; Bunney, S.; Lawson, E.; Chisholm, A.; Farmani, R.; Melville-Shreeve, P. COVID-19 and the Water Sector: Understanding Impact, Preparedness and Resilience in the UK through a Sector-wide Survey. Water Environ. J. 2020, 34, 715.

(10) Bivins, A.; North, D.; Ahmad, A.; Ahmed, W.; Alm, E.; Been, F.; Bhattacharya, P.; Bijlsma, L.; Boehm, A. B.; Brown, J.; Buttiglieri, G.; Calabro, V.; Carducci, A.; Castiglioni, S.; Cetecioglu Gurol, Z.; Chakraborty, S.; Costa, F.; Curcio, S.; De Los Reyes, F. L.; Delgado Vela, J.; Farkas, K.; Fernandez-Casi, X.; Gerba, C.; Gerrity, D.; Girones, R.; Gonzalez, R.; Haramoto, E.; Harris, A.; Holden, P. A.; Islam, M. T.; Jones, D. L.; Kasprzyk-Hordern, B.; Kitajima, M.; Kotlarz, N.; Kumar, M.; Kuroda, K.; La Rosa, G.; Malpei, F.; Mautus, M.; McLellan, S. L.; Medema, G.; Meschke, J. S.; Mueller, J.; Newton, R. J.; Nilsson, D.; Noble, R. T.; Van Nuijs, A.; Peccia, J.; Perkins, T. A.; Pickering, A. J.; Rose, J.; Sanchez, G.; Smith, A.; Stadler, L.; Stauber, C.; Thomas, K.; Van Der Voorn, T.; Wigginton, K.; Zhu, K.; Bibby, K. Wastewater-Based Epidemiology: Global Collaborative to Maximize Contributions in the Fight against COVID-19. Environ. Sci. Technol. 2020, 54 (13), 7754-7757.

(11) Usman, M.; Farooq, M.; Hanna, K. Existence of SARS-CoV-2 in Wastewater: Implications for Its Environmental Transmission in Developing Communities. Environ. Sci. Technol. 2020, 54 (13), 77587759.

(12) Garrido-Baserba, M.; Corominas, L.; Cortés, U.; Rosso, D.; Poch, M. The Fourth-Revolution in the Water Sector Encounters the Digital Revolution. Environ. Sci. Technol. 2020, 54 (8), 4698-4705.

(13) Roidt, M.; Chini, C. M.; Stillwell, A. S.; Cominola, A. Unlocking the Impacts of COVID-19 Lockdowns: Changes in Thermal Electricity Generation Water Footprint and Virtual Water Trade in Europe. Environ. Sci. Technol. Lett. 2020, 7, 683.

(14) Balacco, G.; Totaro, V.; Iacobellis, V.; Manni, A.; Spagnoletta, M.; Piccinni, A. F. Influence of COVID-19 Spread on Water Drinking Demand: The Case of Puglia Region (Southern Italy). Sustainability 2020, 12 (15), 5919.

(15) Faust, K. M.; Abraham, D. M.; McElmurry, S. P. Water and Wastewater Infrastructure Management in Shrinking Cities. Public Work. Manag. Policy 2016, 21 (2), 128-156.

(16) Varis, O.; Biswas, A. K.; Tortajada, C.; Lundqvist, J. Megacities and Water Management. Int. J. Water Resour. Dev. 2006, 22 (2), 377394.

(17) Faure, J. C.; Faust, K. M. Socioeconomic Characteristics versus Density Changes: The Operational Effects of Population Dynamics on Water Systems. Sustainable and Resilient Infrastructure 2020, 1.

(18) Kaminsky, J.; Faust, K. M. Transitioning from a Human Right to an Infrastructure Service: Water, Wastewater, and Displaced Persons in Germany. Environ. Sci. Technol. 2017, 51 (21), 1208112088.

(19) Faust, K. M.; Abraham, D. M. Evaluating the Feasibility of Decommissioning Residential Water Infrastructure in Cities Facing Urban Decline. In ASCE Construction Research Congress, Atlanta, GA, 2014; pp 1229-1238.

(20) Faust, K. M.; Abraham, D. M.; DeLaurentis, D. Coupled Human and Water Infrastructure Systems Sector Interdependencies: Framework Evaluating the Impact of Cities Experiencing Urban Decline. Journal of Water Resources Planning and Management 2017, 143 (8), 04017043.

(21) Zhuang, J.; Sela, L. Impact of Emerging Water Savings Scenarios on Performance of Urban Water Networks. Journal of Water Resources Planning and Management 2020, 146 (1), 04019063.

(22) United Nations. Sustainable Development Goal 9. https:// www.un.org/sustainabledevelopment/infrastructure-industrialization (accessed 2020-08-19).

(23) American Water Works Association. COVID-19 Water Sector Impact Survey (March 10-16, 2020). 2020.

(24) Saldaña, J. The Coding Manual for Qualitative Researchers, 2nd ed.; Sage Publications: London, 2013.

(25) Mansoor, S. President Trump Extends Federal Social Distancing Guidelines Until End of April. TIME. March 29, 2020. 
(26) Strauss, A.; Corbin, L. Basics of Qualitative Research: Techniques and Procedures for Developing Grounded Theory, 2nd ed.; Sage Publications: London, 1998.

(27) U.S. Environmental Protection Agency. 2006 Community Water System Survey; 2006; Vol. I.

(28) De Vries, H.; Elliott, M. N.; Kanouse, E. D.; Teleki, S. S. Using Pooled Kappa to Summarize Interrater Agreement across Many Items. Field methods 2008, 20 (3), 272-282.

(29) Kane, J.; Tomer, A. Renewing the Water Workforce: Improving Water Infrastructure and Creating a Pipeline to Opportunity; The Brookings Institution, 2018.

(30) Poleacovschi, C.; Javernick-Will, A.; Tong, T. The Link between Knowledge Sharing Connections and Employee Time Savings: A Social Network Analysis. Constr. Manag. Econ. 2017, 35 (8-9), 455-467.

(31) U.S. Environmental Protection Agency. National Primary Drinking Water Regulations; 2009.

(32) Spearing, L. A.; Faust, K. M. Cascading System Impacts of the 2018 Camp Fire in California: The Interdependent Provision of Infrastructure Services to Displaced Populations. International Journal of Disaster Risk Reduction 2020, 50, 101822.

(33) American Water Works Association. State of the Water Industry-Executive Summary. 2020.

(34) Jones, S. H.; Armanios, D. E. Methodological Framework and Feasibility Study to Assess Social Equity Impacts of the Built Environment. Journal of Construction Engineering and Management 2020, 146 (11), 05020016. 